\title{
Awareness, risk perception and behavioural intention in patients with a myocardial infarction
}

\author{
Debbie ten Cate ${ }^{* 1}$, Claudia J. Gamel ${ }^{2}$, Berna G.M. Sol ${ }^{3}$ \\ ${ }^{1}$ Institute for Nursing Studies, Hogeschool Utrecht, Netherlands \\ ${ }^{2}$ Division Woman and Baby, University Medical Center Utrecht and Faculty, Clinical Health Sciences, Faculty of Medicine, \\ Utrecht University, Netherlands \\ ${ }^{3}$ University of Applied Sciences, Amsterdam School of Health Professions Nursing, Netherlands.
}

Received: August 19, 2014

DOI: $10.5430 /$ cns.v3n2p8
Accepted: November 16, 2014 Online Published: December 11, 2014

URL: http://dx.doi.org/10.5430/cns.v3n2p8

\begin{abstract}
Introduction: Background: There is limited research on the association of awareness and risk perception of cardiovascular risk factors with behavioural intention to adhere to lifestyle targets related to risk factors such as smoking, abdominal obesity, physical inactivity, excessive alcohol intake and inadequate fruit and vegetable intake. The association of all risk factors concurrently and in patients who had a myocardial infarction less than one month ago has not been previously investigated. Objective: To describe the association of awareness and risk perception of cardiovascular risk factors with behavioural intention in respect to aforementioned lifestyle targets in patients within one month of hospitalization for a myocardial infarction.
\end{abstract}

Methods: In a cross-sectional observational study, 31 patients with a recent diagnosis of a myocardial infarction were included. Awareness, risk perception and behavioural intention were measured with a questionnaire. Data were analyzed using linear regression in which behavioural intention was divided into: risk factor not present, low and high intention.

Results: The mean score for awareness was $3.9 \pm 1.5$ (scale range from 0 to 14) and for risk perception $-0.7 \pm 1.4$ (scale range from -3 to +3 ). Awareness and risk perception of cardiovascular risk factors were not associated with behavioural intention in smoking, overweight, physical inactivity and insufficient intake of fruit and vegetables.

Conclusion: Patients with a myocardial infarction less than one month ago have a low awareness and low risk perception of cardiovascular risk factors and this is not associated with behavioural intention to adhere to lifestyle targets related to risk factors.

Key Words: Awareness, Risk perception, Behavioural intention, Cardiovascular risk factors, Lifestyle targets, Myocardial infarction

\section{Introduction}

Myocardial infarction (MI) is defined "by pathology as myocardial cell death due to prolonged ischaemia". ${ }^{[1]}$ Worldwide and in Europe, MI is the most frequent cause of mortality and morbidity. ${ }^{[2,3]}$ Although a reduction in mortality from MI is seen in Europe, the number of patients with an
MI is increasing. ${ }^{[2]}$ These patients have a high risk of a new MI or death. ${ }^{[4]}$

More than $90 \%$ of the risk of MI is associated with the presence of risk factors such as hypertension, hypercholesterolaemia, diabetes, smoking, abdominal obesity, physical inactivity, excessive alcohol intake, inadequate fruit and

\footnotetext{
*Correspondence: Debbie ten Cate; Email: Debbie.tencate@hu.nl; Address: Institute for Nursing Studies, Hogeschool Utrecht, PO Box 573, 3500
} AN Utrecht, the Netherlands. 
vegetable intake and psycho-social factors. ${ }^{[5]}$ Reduction, treatment and control of these risk factors leads to a reduced risk of MI. ${ }^{[4,5]}$ Guidelines are available in which nonpharmacological (focused on lifestyle) and pharmacological goals are specified. However the goals are not achieved in clinical practice and mortality from MI remains high. ${ }^{[6]}$ Although it is difficult, patients can influence the lifestyle related risk factors such as smoking, overweight, physical inactivity, excessive alcohol intake and fruit and vegetable intake through their own behaviour. ${ }^{[7,8]}$

A number of factors influence behavioural change. In this study, a conceptual model is used to identify the relationship among these factors (see Figure 1). The conceptual model is based on the Theory of Planned Behavior (TBP), Health Counseling Model (HCM) and Health Action Process Approach (HAPA). ${ }^{[9-11]}$ According to TBP, behavioural intention is a strong predictor of behavioural change. Behavioural intention encompasses motivating factors that influence behaviour. These factors are an indication of the degree to which a person is prepared to try and how much effort a person plans to give in order to perform the behaviour. The stronger the behavioural intention, the greater the chance that the behaviour will change. ${ }^{[9]}$ Awareness (according to HCM) and risk perception (according to HAPA) are two determinants of behavioural intention whereby a high level of awareness and risk perception are associated with a high behavioural intention. ${ }^{[10,11]}$ Awareness refers to the insight that and how a specific behaviour influences the development, continuation and resolution of a complaint. ${ }^{[10]}$ Risk perception is the belief that he or she is vulnerable to a specific illness. ${ }^{[11]}$

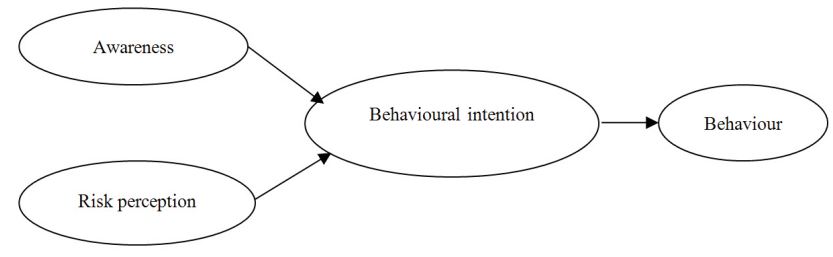

Figure 1: Conceptual model of associations among awareness and behavioural intention, risk perception and behavioural intention, and behavioural intention and behaviour. ${ }^{[9-11]}$

The association between awareness or risk perception of cardiovascular risk factors and behavioural intention for a number of lifestyle related risk factors seems inconclusive, both positive relationship ${ }^{[12]}$ and no relationship are reported. ${ }^{[13-15]}$

The current Dutch Heart Rehabilitation Standard directs professionals to provide patient education after hospital discharge of a patient with MI. ${ }^{[16]}$ Patient education after discharge is indicated because it is difficult to provide information during the short length of hospitalization (5 days or less). Also impaired readiness to learn may be seen during hospitalization because of the physical and emotional condition after such a stressful situation. ${ }^{[17]}$ Yet in practice encounters after hospitalization, cardiac (rehabilitation) nurses seem to take for granted that a patient who has undergone an MI has a high level of awareness and perceived risk of cardiovascular risk factors and that this has a positive influence of behavioural intention for the lifestyle related risk factors. Experience on a Dutch cardiology unit attests to minimal use of guidelines for cardiac rehabilitation concerning behavioural change and lifestyle when providing patient education. Also the first 5 months after hospitalization for MI are extremely stressful. ${ }^{[18]}$ Patients experience anxiety, depression, uncertainty, loneliness and have a weakened condition. ${ }^{[17]}$ Especially in the first month post MI, patients are extremely vulnerable. Consequently, this highlights the need for professional support, advice and information over the diagnosis, the resumption of physical activities and prevention oriented lifestyle changes. ${ }^{[19,20]}$ The association of awareness and risk perception with behavioural intention is not fully understood for lifestyle related cardiovascular risk factors smoking, overweight, physical inactivity, excessive alcohol intake and inadequate intake of fruit and vegetables in patients in the first month post MI. If this association is not fully understood in clinical practice, it cannot be taken into account when educating and coaching post MI patients. Given this lack of insight, the present study was designed to examine the association of awareness and risk perception of cardiovascular risk factors with behavioural intention concerning the aforementioned lifestyle related risk factors in patients within one month after hospitalization for MI.

\section{Methods}

\subsection{Design, study population and procedure}

A cross-sectional observational research design was used to collect data between January and April 2010. The research population consisted of patients who were diagnosed with MI according to the European guideline. ${ }^{[21]}$ Participants were eligible if they were admitted within the last four weeks to a top clinical hospital in the Netherlands and if they remained under care of the cardiology department after discharge. Additional inclusion criteria were: speaks and writes. Dutch, able to give informed consent, without serious or terminal illnesses, and had no more than two earlier diagnoses of MI. Also patients had at least two of the following lifestyle related cardiovascular risk factors: smoking (all types of tobacco), ${ }^{[2]}$ overweight defined as Body Mass Index or BMI $>25 \mathrm{~kg} / \mathrm{m}^{2}$ or waist circumference $>$ $80 \mathrm{~cm}$ (women) or $>94 \mathrm{~cm}$ (men), physical inactivity (< 5 days/week with 30 minutes/day moderate physical activity), more than recommended alcohol intake (for women $>$ 2 glasses/day and for men $>3$ glasses/day), and inadequate fruit and vegetable consumption $(<2$ pieces of fruit or $<200$ g. vegetables/day). ${ }^{[7]}$ 
Convenience sampling was used. After discharge, eligible patients were called by the nurse researcher and asked to participate. Recruitment continued until 25 patients were included. This sample size was based on statistical analysis requirements to include a minimum of five times the number of independent variables, ${ }^{[23]}$ in this situation five variables that represent behavioural intention for each of the five lifestyle related risk factors. Participants returned to a cardiology ward in the hospital to complete the self-report questionnaire with the researcher in attendance in order to ensure complete answers. Informed consent was obtained in accordance with the hospital's policy. The independent ethics committee of the hospital was consulted to determine if approval was needed. Because this is an observational study, approval was not necessary.

\subsection{Measures}

Demographic and medical variables included: diagnosis and date of MI, number of previous MI; serious illnesses or terminal illness, sex, age, educational level, history of cardiovascular disease, hypertension, hypercholesterolaemia, diabetes and family history. These variables were systematically extracted from the electronic patient record. Missing data were obtained from the patient.

In this study the present behaviour of cardiovascular risk factors was reported. This included: smoking, overweight, physical inactivity, more than recommended alcohol intake, and inadequate fruit and vegetable consumption as well as risk factor awareness, risk perception and behavioural intention. No one instrument was available so different instruments were combined. The constructed self-report questionnaire consisted of 15 questions, 15 suppositions, and 3 physical assessments. The presence of the risk factors was established with valid and user friendly Dutch instruments: 2 questions smoking, ${ }^{[24]} 4$ questions physical inactivity, 2 questions more than recommended alcohol intake, and 4 questions inadequate fruit and vegetable consumption. ${ }^{[25]}$ Three measurements (length and weight for calculation BMI plus waist circumference) were used to determine overweight. ${ }^{[26,27]}$

Because no Dutch instruments were available, valid nonDutch instruments ${ }^{[13,28-33]}$ were selected to measure awareness, risk perception and behavioural intention associated with the risk factors smoking, overweight, physical inactivity, more than recommended alcohol intake, and inadequate fruit and vegetable consumption. These items were translated according to the procedure described by Brislin. ${ }^{[34]}$ Subsequently the clarity, validity and comprehensiveness of the items in the Dutch questionnaire were judged by an expert specialized in the field conform the second phase of Lynn's procedure. ${ }^{[35]}$ Additionally, the questionnaire was pretested with one patient to determine clarity of the questionnaire and how much time was needed to administer the questionnaire. ${ }^{[36]}$ Awareness was measured with
1 open question ("What are the risk factors for myocardial infarction?") concerning 14 cardiovascular risk factors. ${ }^{[28]}$ One point was scored for each correctly named risk factor. The minimum score was 0 and maximum 14 . A total mean score was calculated. The lower the score, the lower the awareness. The 2 questions concerning risk perception ("Compared to other people of the same age and gender, how likely is it that you would have (a) myocardial infarction (b) other severe cardiovascular events?") ${ }^{[13]}$ were scored with a 7 point Likert scale (minimum score -3, maximum score +3 ). The mean score was calculated. The lower the score, the lower the risk perception. Behavioural intention was measured using supposition statements; 3 statements for smoking, ${ }^{[29]} 2$ statements about overweight, ${ }^{[30]} 5$ statements for more than recommended alcohol intake, ${ }^{[31]}$ and 2 statements concerning inadequate fruit and vegetable consumption. ${ }^{[32]}$ All statements were scored using a 7 point Likert scale (smoking: minimum score 0 , maximum score +7 ; overweight: minimum score -3 , maximum score +3 ; more than recommended alcohol intake: minimum score 3 , maximum score +3 ; inadequate fruit and vegetable consumption: minimum score 0 , maximum score +7 ) and a mean score was calculated. Behavioural intention concerning physical inactivity was measured with 3 statements ${ }^{[33]}$ each scored with a 4 point Likert scale (minimum 0, maximum +4$)$. The mean score was calculated. The lower the score, the lower the behavioural intention.

The internal consistency was determined by calculating the Cronbach's $\alpha$ of the correlations among questions or statements and the homogeneous subscales of the instrument. An adequate internal consistency was set at Cronbach's $\alpha$ $>.60^{[37]}$ and a good internal consistency was identified as Cronbach's $\alpha$ between .70 en .95. ${ }^{[38]}$

\subsection{Statistical analysis}

All data were analyzed with SPSS 17.0. The mean and standard deviation (sd) were used to describe numerical variables with a normal distribution. When a skewed distribution was found, the median and interquartile range were used. $^{[39]}$ Categorical variables were described using percentages. The association of awareness and risk perception of cardiovascular risk factors with behavioural intention of lifestyle related risk factors was determined with linear regression. ${ }^{[23]}$ The dependent variable was awareness or risk perception of cardiovascular risk factors. Behavioural intention for each of the five lifestyle related risk factors was the independent variable. Behavioural intention for each lifestyle related risk factor was divided into three groups: risk factor not present, low intention and high intention. Results of the linear regression analysis were presented as bcoefficient (B), which is the estimation of awareness or risk perception for the five lifestyle related risk factors; also as the $95 \%$ reliability interval and the correlation coefficient $\left(\eta^{2}\right)$ which explains the variation of awareness or risk per- 
centage determined by the five lifestyle risk factors. ${ }^{[23]}$ The linear regression analysis was corrected for the confounding variables sex, age, education level and number of lifestyle related cardiovascular factors. The significance level was set at .05 (two-sided). Missing values were not included in the analysis.

\section{Results}

\subsection{Study population}

A total of 241 patients were screened. Of the 63 patients who met the selection criteria, 17 could not be contacted and 13 did not give Informed Consent. The sample consisted of 32 patients and useable data were collected from 31 patients (see Figure 2). Data collection took place between 15-25 days post MI.

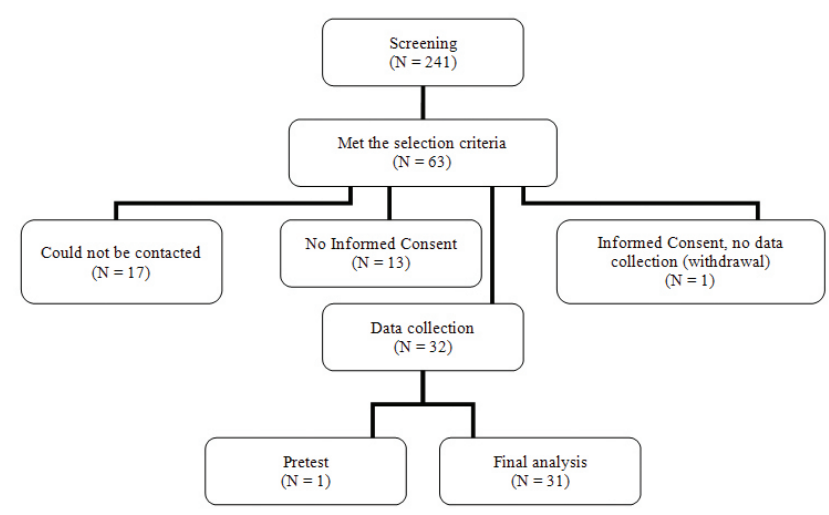

Figure 2: Sample description diagram

\subsection{Descriptive data}

More than one third (37\%) of the patients were men and nearly half $(48 \%)$ of the patients have a low education level. The mean age was 58.7 years $( \pm 8.8)$. Few had a history of CVD: MI (10\%), CVA (3\%), PAD (3\%) and AAA $(0 \%)$ (Table 1 includes further details and a list of abbreviations).

\subsection{Presence of cardiovascular risk factors}

Patients had two (26\%), three $(55 \%)$ or four $(19 \%)$ life style related cardiovascular risk factors. Physical inactivity (97\%), overweight (94\%) and inadequate fruit and vegetable intake $(77 \%)$ were seen most often. In contrast, smoking (19\%) and alcohol intake above recommended limit (6\%) were less often reported (see Table 2).

\begin{tabular}{ll} 
Table 1: Demographic and medical data $(\mathrm{N}=31)$ \\
\hline Variable & $\mathbf{n}(\%)$ \\
\hline Male sex & $27(87)$ \\
Age (years) & $58.7 \pm 8.8^{*}$ \\
Education & \\
Low & $15(48)$ \\
Middle & $11(36)$ \\
High & $5(16)$ \\
History of cardiovascular disease (CVD) & \\
None & $26(84)$ \\
Coronary heart disease & $3(10)$ \\
Cerebrovascular disease & $1(3)$ \\
Peripheral arterial disease & $1(3)$ \\
Abdominal aortic aneurysm & $0(0)$
\end{tabular}

\section{Frequency MI in history"}

$\begin{array}{ll}0 & 28(90) \\ 1 & 2(7) \\ 2 & 1(3) \\ >2 & 0(0)\end{array}$

Hypertension $^{\dagger} \quad 19(61)$

Hypercholesterolaemia $\quad 27$ (87)

Diabetes mellitus $^{\dagger \dagger} \quad 5(16)$

Family history 10 (32)

Time between MI and data collection (days) 15-25

* Data represent mean $\pm \mathrm{sd} ;{ }^{\S}$ Low $=$ primary school, Dutch levels of LBO, MAVO, VMBO; Middle or high school education $=$ Dutch levels of HAVO, VWO, MBO; High or professional, university education $=$ Dutch levels of $\mathrm{HBO}$, WO; ${ }^{\circ}$ Recent diagnosis of MI not included. ${ }^{\dagger}$ Systolic blood pressure $\geq 140 \mathrm{mmHg}$ and/or diastolic blood pressure $\geq 90 \mathrm{mmHg}$ or use of anti-hypertensive drugs.

\# Total cholesterol level $\geq 4.5 \mathrm{mmol} / \mathrm{L}$ and/or LDL-cholesterol $\geq 2.5 \mathrm{mmol} / \mathrm{L}$ or use of lipid-lowering medication.

${ }^{\dagger}$ Fasting glucose level $\geq 6.0 \mathrm{mmol} / \mathrm{L}$ or use of glucose-lowering medication.

"Father and/or brother with CVD before 55 years or mother and/or daughter with CVD before 65 years.

\subsection{Awareness, risk perception and behavioural in- tention}

In this study, Cronbach's $\alpha$ was calculated for variables measured with at least two questions namely: risk perception .85 as well as behavioural intention by: smoking .88 , physical inactivity .83 , inadequate fruit and vegetable intake .85 and overweight .68. Internal consistency for the first four scales was good ${ }^{[38]}$ and acceptable for the last scale. ${ }^{[37]}$ Internal consistency for behavioural intention by alcohol exceeding recommendations was not calculated because this concerned only two participants. Subsequently no further results are reported concerning the behavioural intention regarding the cardiovascular risk factor more than recommended alcohol intake.

The mean score for awareness was $3.9 \pm 1.5$ (scale ranges from 0 to 14) which indicates low awareness of the possible 14 risk factors. The most frequently reported risk factors were: smoking ( $81 \%$ of the patients), fat consumption (65\% of the patients), and physical inactivity (52\% of the patients). In contrast, patients were least aware of the risk factors sex and age ( $0 \%$ of the patients named these factors) 
and inadequate fruit and vegetable intake (named only by $3 \%$ of the patients).

Table 2: Lifestyle related cardiovascular risk factors $(\mathrm{N}=$ 31)

\begin{tabular}{|c|c|}
\hline Variable & n (\%) \\
\hline \multicolumn{2}{|l|}{ Number of lifestyle related risk factors ${ }^{\S}$} \\
\hline 0 & $0(0)$ \\
\hline 1 & $0(0)$ \\
\hline 2 & $8(26)$ \\
\hline 3 & $17(55)$ \\
\hline 4 & $6(19)$ \\
\hline 5 & $0(0)$ \\
\hline BMI $\left(\mathrm{kg} / \mathrm{m}^{2}\right)$ & $27.4 \pm 2.7^{\natural}$ \\
\hline \multicolumn{2}{|l|}{ Waist circumference $(\mathrm{cm})$} \\
\hline Female & $102 \pm 6^{\pi}$ \\
\hline Male & $102 \pm 8^{\pi}$ \\
\hline \multicolumn{2}{|l|}{ Alcohol } \\
\hline Never $/<$ once a month & $13(42)$ \\
\hline Monthly & $1(3)$ \\
\hline Weekly & $8(26)$ \\
\hline Daily & $9(29)$ \\
\hline Fruit (pieces per week) & $14(7-14)^{\dagger}$ \\
\hline Vegetable (ounce per week) & $10(8-14)^{\dagger}$ \\
\hline Actual smokers & $6(19)$ \\
\hline Smoker until hospitalized for most recent MI & $12(39)$ \\
\hline $\mathrm{BMI} \geq 25 \mathrm{~kg} / \mathrm{m}^{2}$ & $24(77)$ \\
\hline $\begin{array}{l}\text { Waist circumference } \geq 80 \mathrm{~cm} \text { (female) or } \geq 94 \\
\mathrm{~cm} \text { (male) }\end{array}$ & $28(90)$ \\
\hline Physical inactivity & $30(97)$ \\
\hline Alcohol use exceeds recommendations & $2(6)$ \\
\hline Inadequate intake of fruit and vegetables & $24(77)$ \\
\hline
\end{tabular}

§ Smoking (all forms of tobacco use); overweight (BMI $\geq 25 \mathrm{~kg} / \mathrm{m}^{2}$ or waist circumference $\geq$ $80 \mathrm{~cm}$ (female) or $\geq 94 \mathrm{~cm}$ (male)); physical inactivity $(<5$ days a week 30 minutes a day medium physical activity); alcohol use exceeds recommendations ( $\geq 3$ (female) of $\geq 4$ (male) glasses of alcohol per day); inadequate intake of fruit and vegetables $(<200$ grams of vegetable and 2 pieces of fruit per day)

"Data are mean \pm sd.

${ }^{\dagger}$ Data are median with interquartile range.

The mean score for risk perception (scale ranges from -3 to +3 ) was $-0.7 \pm 1.4$, indicative of low risk perception. The mean scores for behavioural intention were calculated only when patients indicated the presence of one of the five lifestyle cardiovascular risk factors targeted in this study. The behaviour intention for smoking (scale range from 0 to 7) was $5.7 \pm 2.1$ (high behavioural intention), overweight was $0.6 \pm 1.7$ (average behavioural intention with scale range from -3 to +3 ), physical inactivity $3.7 \pm 0.6$ (very high behavioural intention) (scale range from 0 to +4 ), and inadequate fruit and vegetable intake $6.1 \pm 0.9$ (high behavioural intention) (scale range from 0 to +7 ) (see Table $3)$.

\subsection{Association of awareness and risk perception with behavioural intention}

Awareness was lower by patients with low and high behavioural intentions than by patients without the presence of cardiovascular risk factors smoking, overweight, physical inactivity and inadequate fruit and vegetable intake. Although this was not at significant level, and in linear regression analysis adjusted for confounding variables (see Table 4).

Risk perception scores showed a similar pattern as the awareness scores. Not significant, and in linear regression analysis adjusted for confounding variables, risk perception was lower by patients with low and high behavioural intentions than by patients without the cardiovascular risk factors. This pattern was seen for smoking, overweight and inadequate consumption of fruit and vegetables. The risk perception scores were high, yet not significant, in patients with low and high physical inactivity behavioural (see Table 4).

\section{Discussion}

When conducted in 2010, this was the first Dutch study of the association of awareness and risk perception with behavioural intention for five lifestyle related cardiovascular risk factors; 1) smoking, 2) overweight, 3) physical inactivity, 4) alcohol intake exceeding recommendations, and 5) inadequate fruit and vegetable intake in patients one month after hospital admission for MI. No associations were found. A low level of awareness and low risk perception were seen. Behavioural intention to adhere to targets for smoking, physical inactivity and insufficient intake of fruit and vegetables were high and low by overweight.

In the conceptual model used in this study (see Figure 1), a high level of awareness and high risk perception were expected to be associated with a high behavioural intention. The hypothesized relationship was not seen in this sample of post MI patients. Possibly awareness and risk perception are not decisive determinants of behavioural intention to adhere to lifestyle targets related to cardiovascular risk factors. Or perhaps in accordance with the HAPA, risk perception is insufficient alone to explain behavioural intention. ${ }^{[11,40]}$ It is plausible in the HCM that behavioural intention is influenced by other determinants or outcome expectations and self-efficacy, in addition to risk perception. ${ }^{[10]}$

Behavioural intention was high for smoking, physical inactivity and inadequate fruit and vegetable intake. This may reflect actual intentions or this finding may represent social desirable answers because patients knew that a high behavioural intention was expected. A number of patients remarked that they did not have risk factors yet risk factors were clearly present based on the Dutch guidelines. ${ }^{[7]}$ Perhaps they did not recognize that risk factors were applicable 
in their own situation or they minimalized the importance. One possible explanation is associated with the nature of an MI. It is an acute rather than chronic situation. ${ }^{[41]}$ Not recognizing one's own risk factors and a low level of awareness and risk perception of cardiovascular risk factors can be associated with the acute nature of an MI. An alternative explanation is denial caused by the stressful situation (MI) and extreme stress experienced during the first months after an MI. ${ }^{[17,18]}$ Denial of perceived risk in healthy people was previously investigated. ${ }^{[42]}$ When MI is envisioned as an acute event or denial of the stressful event occurs, then patients do not have to see themselves as being sick, which makes it unnecessary to change behaviours and to follow a healthy lifestyle.

Table 3: Awareness, risk perception and behavioural intention concerning lifestyle related cardiovascular risk factors

\begin{tabular}{|c|c|}
\hline Awareness (1 question concerning 14 cardiovascular risk factors) ${ }^{\dagger}(\mathrm{n}=31)$ & $3.9 \pm 1.5^{\S}$ \\
\hline \multicolumn{2}{|l|}{ Frequency of awareness for all 14 cardiovascular risk factors: } \\
\hline Hypertension & $16^{\pi}$ \\
\hline Hypercholesterolaemia & $19^{\pi}$ \\
\hline Diabetes mellitus & $13^{\pi}$ \\
\hline Family history & $23^{9}$ \\
\hline Smoking & $81^{\natural}$ \\
\hline Overweight & $26^{\pi}$ \\
\hline Physical inactivity & $52^{\pi}$ \\
\hline Excessive use of alcohol & $32^{9}$ \\
\hline Insufficient intake of fruit and vegetables & $3^{\pi}$ \\
\hline Fat intake & $65^{\pi}$ \\
\hline Salt intake & $10^{\pi}$ \\
\hline Psychosocial factors & $48^{\pi}$ \\
\hline Age & 0 \\
\hline Sex & 0 \\
\hline Mean risk perception (based on 2 questions) ${ }^{\ddagger}(n=31)$ & $-0.7 \pm 1.4^{\S}$ \\
\hline Mean behavioural intention smoking (based on 3 propositions) ${ }^{\dagger \dagger}\left(\mathrm{n}=6^{*}\right)$ & $5.7 \pm 2.1^{\S}$ \\
\hline Mean behavioural intention overweight (based on 2 propositions) ${ }^{9 \pi}\left(n=29^{*}\right)$ & $0.6 \pm 1.7^{\S}$ \\
\hline Mean behavioural intention physical inactivity (based on 3 propositions) ${ }^{\text {邦 }}\left(n=29^{*}\right)$ & $3.7 \pm 0.6^{\S}$ \\
\hline Mean behavioural intention inadequate fruit and vegetable intake (based on 2 propositions) ${ }^{\#}\left(\mathrm{n}=24^{*}\right.$ ) & $6.1 \pm 0.9^{\S}$ \\
\hline
\end{tabular}

No associations were found between awareness and risk perception of cardiovascular risk factors with behavioural intention in smoking, overweight, physical inactivity and insufficient intake of fruit and vegetables. In several studies the association between awareness or risk perception of cardiovascular risk factors and behavioural intention for a number of lifestyle related risk factors seems inconclusive, both positive relationship ${ }^{[12]}$ and no relationship are reported. ${ }^{[13-15]}$ A high level of perceived risk of smoking associated health problems was related to a high behavioural intention to stop smoking in healthy people 19-69 years of age. ${ }^{[12]}$ No associations were found between the degree of perceived risk of MI or other serious cardiovascular diseases and the level of behavioural intention to become physically active in patients with and without cardiovascular diseases and diabetes between $18-60$ years of age. ${ }^{[13]}$ Similarly, no association was seen in the degree of perceived risk of cardiovascular disease and the level of behavioural intention to increase fruit and vegetable intake in women 30-64 years old. ${ }^{[14]}$ Healthy women 18-24 years old showed a low level of awareness of cardiovascular risk factors and a low behavioural intention to change smoking, overweight and physical inactivity behaviours. However the presence of relationships is unclear. ${ }^{[15]}$ 
Table 4: Awareness and risk perception of cardiovascular risk factors associated with behavioural intention in lifestyle related cardiovascular risk factors $(\mathrm{N}=30)^{\S}$

\begin{tabular}{|c|c|c|c|c|c|c|}
\hline & \multicolumn{3}{|c|}{ Awareness } & \multicolumn{3}{|c|}{ Risk perception } \\
\hline & B & $95 \%$ CI & $\eta^{2}$ & B & $95 \%$ CI & $\eta^{2}$ \\
\hline Smoking & & & .054 & & & .05 \\
\hline Low intention $\left(\mathrm{n}=3^{*}\right)$ & $-1.8^{\dagger}$ & $-5.7-2.1$ & & $-1.6^{\dagger}$ & $-5.2-2.0$ & \\
\hline High intention $\left(\mathrm{n}=3^{*}\right)$ & $-1.3^{\dagger}$ & $-5.8-3.1$ & & $-1.3^{\dagger}$ & $-5.3-2.8$ & \\
\hline Overweight & & & .108 & & & .036 \\
\hline Low intention $\left(\mathrm{n}=13^{*}\right)$ & $-3.2^{\dagger}$ & $-8.0-1.5$ & & $-1.6^{\dagger}$ & $-6.0-2.7$ & \\
\hline High intention $\left(\mathrm{n}=16^{*}\right)$ & $-2.9^{\dagger}$ & $-7.5-1.7$ & & $-1.5^{\dagger}$ & $-5.7-2.7$ & \\
\hline Physical inactivity & & & .133 & & & .017 \\
\hline Low intention $\left(\mathrm{n}=13^{*}\right)$ & $-3.0^{\dagger}$ & $-6.8-0.9$ & & $0.8^{\dagger}$ & $-2.7-4.3$ & \\
\hline High intention $\left(\mathrm{n}=16^{*}\right)$ & $-2.5^{\dagger}$ & $-6.2-1.2$ & & $0.5^{\dagger}$ & $-2.9-3.9$ & \\
\hline Insufficient intake of fruit and vegetables & & & .134 & & & .062 \\
\hline Low intention $\left(\mathrm{n}=14^{*}\right)$ & $-2.4^{\dagger}$ & $-7.0-2.2$ & & $-2.1^{\dagger}$ & $-6.3-2.1$ & \\
\hline High intention $\left(\mathrm{n}=10^{*}\right)$ & $-3.0^{\dagger}$ & $-7.3-1.4$ & & $-2.0^{\dagger}$ & $-6.0-2.0$ & \\
\hline
\end{tabular}

The study population consisted mostly of middle-aged men as compared to the general Dutch patient population with a diagnosis of MI. Patients with high co-morbidity were excluded from the study. Our patients had an average of three lifestyle related risk factors. Overweight, physical inactivity and inadequate fruit and vegetable intake were seen most often. Furthermore $61 \%$ had hypertension and $87 \%$ hypercholesterolaemia.

The level of awareness and risk perception was surprisingly low given the presence of cardiovascular risk factors in combination with the diagnosis MI. Low awareness also was found in healthy women 18 to 24 years old, ${ }^{[15]}$ and low risk perception has been reported in healthy people with a mean age of 52 years. ${ }^{[42]}$ The degree of risk perception of patients with CVD and diabetes was higher than that of healthy people and subsequently the role of illness was named as possible explanation for these findings. ${ }^{[13]}$

In our study, the presence of cardiovascular risk factors and the diagnosis of MI appeared to have no influence on increasing awareness and risk perception of cardiovascular risk factors. This might suggest a discrepancy between research and practice. Nurses have the general impression that patients who have had an MI have a higher level of awareness and risk perception of cardiovascular risk factors. On the other hand underrepresentation of patients who had an MI in the past in this study was possible. Only three patients were diagnosed with MI for the second or third time compared to 28 patients with a first diagnosis of MI. Patients with a history of MI may yet have higher awareness and risk perception. The findings of our study are noteworthy because findings from the patient perspective concerning lifestyle related cardiovascular risk factors have not been reported previously.

Patients need individualized information and education during the first months post MI. ${ }^{[20]}$ They find it difficult to apply standardized information to their own situation and do not know what information is relevant to their own specific problems. ${ }^{[17]}$ In our clinical setting, individualized and group information is given. Especially group format can be inadequate to individualize information for patients. In our study population, almost half of the patients had a low education level. These findings suggest that consideration of individual format for patients with a level of education level may be needed to minimize misunderstanding.

The study had limitations. Selection bias was possible because of the convenience sampling technique and inclusion criteria. Also only 31 of the eligible 63 patients consented to participate. Consequently differences were possible between participants and non-participants ${ }^{[36]}$ because data over non-participants were not available. For example, patients who were still in hospital because of complications of the MI were neither screened nor included. Informational bias and socially desirable answers ${ }^{[36]}$ were possible because participants completed the questionnaire in the 
presence of the researcher. Sample size was small $(\mathrm{N}=31)$. Selection of more than one hospital would have increased the sample size and enhanced external validity. ${ }^{[36]}$ These limitations mean that caution needs to be taken when generalizing findings, ${ }^{[43]}$ to the research population of patients four weeks post MI.

\section{Conclusion}

Patients 15-25 days post MI reported low awareness and low risk perception of cardiovascular risk factors. Behavioural intentions to adhere to targets for smoking, physical inactivity and insufficient intake of fruit and vegetables were high as compared to low intention to adhere to targets for overweight. Awareness and risk perception of cardiovascular risk factors were not associated with behavioural intention in smoking, overweight, physical inactivity and insufficient intake of fruit and vegetables.

\section{Implications for practice and future re- search}

Further investigation is indicated to determine the possible influence of other determinants than awareness and risk per- ception on behavioural intention concerning lifestyle related cardiovascular risk factors in the first month post MI. In specific, the motivating factors that influence behaviour change in cardiac patients is needed. Another focus for future research is the development of valid and reliable instruments to measure awareness and risk perception of patients with MI. It should also be borne in mind what the influence of a stressful situation such as an MI is on the need for information and care in the first month post MI.

Nurses who provide education and information to patients in the first month post MI, need to be cognizant that this patient group may have a low awareness and low perception of cardiovascular risk factors despite the presence of cardiovascular risk factors and the diagnosis of MI.

\section{Acknowledgements}

The authors wish to thank dr. H. Kelder clinical epidemiologist for his advice on the statistical analysis.

\section{Conflicts of Interest Disclosure}

The authors declare that they have no competing interests.

\section{References}

[1] Thygesen K, Alpert JS, Jaffe AS, Simoons ML, Chaitman BR, White HD. Third universal definition of myocardial infarction. Eur Heart J. 2012; 33: 2551-67. PMID:22922414. http://dx.doi.o $\mathrm{rg} / 10.1093$ /eurheartj/ehs 184

[2] Lopez AD, Mathers CD, Ezzati M, Jamison DT, Murray CJL. Global and regional burden of disease and risk factors, 2001: systematic analysis of population health data. Lancet. 2006; 367: 1747-57. http://dx.doi.org/10.1016/S0140-6736 (06) 68770-9

[3] World Health Organization. The world health report 2003: shaping the future. Geneva: World Health Organization, 2003.

[4] Perk J, De Backer G, Gohlke H, Graham I, Reiner Z, Verschuren WMM, et al. European guidelines on cardiovascular disease prevention in clinical practise (version 2012). The Fifth Joint Task Force of the European Society of Cardiology and other societies on cardiovascular disease prevention in clinical practise (constituted by representatives of nine societies and by invited experts). Eur Heart J. 2012; 33: 1635-1701. PMID:22555213. http://dx.doi.org/1 0.1093 /eurheartj/ehs092

[5] Yusuf S, Hawken S, Ôunpuu S, Dans T, Avezum A, Lanas F, et al. Effect of potentially modifiable risk factors associated with myocardial infarction in 52 countries (the INTERHEART study): casecontrol study. Lancet. 2004; 364: 937-52. http://dx. doi .org/1 $0.1016 / \mathrm{S} 0140-6736(04) 17018-9$

[6] Kotseva K, Wood D, De Backer G, De Bacquer D, Pyörälä K, Keil U. EUROASPIREIII: a survey on the life style, risk factors and use of cardioprotective drug therapies in coronary patients from $22 \mathrm{Eu}-$ ropean countries. Eur J Cardiovasc Prev Rehabil. 2009; 16: 121-37. PMID:19287307. http://dx.doi.org/10.1097/HJR.0b013e3 283294b1d

Published by Sciedu Press
[7] Kwaliteitsinstituut voor de gezondheidszorg CBO and Nederlands Huisartsen Genootschap. Multidisciplinaire richtlijn cardiovasculair risicomanagement. Alphen a/d Rijn: van Zuiden; 2006.

[8] Sol BGM, van der Graaf Y, van der Bijl JJ, Goessens BMB, Visseren FLJ. The role of self-efficacy in vascular risk factor management: a randomized controlled trial. Patient Educ Couns. 2008; 71: 191-7. PMID:18242934. http://dx.doi.org/10.1016/j.pec. 2007. 12.005

[9] Ajzen I. The theory of planned behavior. Organizational Behavior and Human Decision Processes. 1991; 50: 179-211. http: //dx.doi.org/10.1016/0749-5978(91)90020-T

[10] Gerards F, Borger R. Health counseling. 4th ed. Baarn: Nelissen; 2006.

[11] Schwarzer R. Self-regulatory processes in the adoption and maintenance of health behaviors: the role of optimism, goals and threats. J Health Psychol. 1999; 4(2): 115-27. PMID:22021474. http: //dx.doi.org/10.1177/135910539900400208

[12] Norman P, Conner M, Bell R. The theory of planned behavior and smoking cessation. Health Psychol. 1999; 18: 89-94. PMID:9925050. http://dx.doi.org/10.1037/0278-6133.18 .1 .89

[13] Luszczynska A, Tryburcy M. Effects of a self-efficacy intervention on exercise: the moderating role of diabetes and cardiovascular diseases. Applied Psychology: an International Review. 2008; 57: 64459. http://dx.doi.org/10.1111/j.1464-0597.2008.00340 . $\mathrm{x}$

[14] Humphries D, Krummel DA. Perceived susceptibility to cardiovascular disease and dietary intake in women. Am J Health Behav. 1999; 23: 250-60. http://dx.doi.org/10.5993/AJHB. 23.4.2

[15] Scott LB, Curbow B. The effect of message frames and CVD risk factors on behavioral outcomes. Am J Health Behav. 2006; 30: 58297. http://dx.doi.org/10.5993/AJHB.30.6.5 
[16] Revalidatiecommissie Nederlandse Vereniging voor Cardiologie/Nederlandse Hartstichting. Multidisciplinaire Richtlijn Hartrevalidatie 2011. Utrecht: Drukkerij Pascal; 2011.

[17] Hanssen TA, Nordrehaug JA, Hanestad BR. A qualitative study of the information needs of acute myocardial infarction patients and their preferences for follow-up contact after discharge. Eur J Cardiovasc Nurs. 2005; 4: 37-44. PMID:15718191. http://dx.doi .org/10.1016/j.ejcnurse.2004.11.001

[18] Moser DK, Dracup KA, Marsden C. Needs of recovering cardiac patients and their spouses: compared views. Int J Nurs Stud. 1993; 30(2): 105-14. http://dx.doi.org/10.1016/0020-7489(93 ) $90060-8$

[19] Thompson DR, Ersser SJ, Webster RA. The experiences of patients and their partners 1 month after a heart attack. J Adv Nurs. 1995; 22: 707-14. PMID:8708190. http://dx.doi.org/10.1046/j.1 365-2648.1995.22040707.x

[20] Turton J. Importance of information following myocardial infarction: a study of the self-perceived information needs of patients and their spouse/partner compared with the perceptions of nursing staff. J Adv Nurs. 1998; 27: 770-78. PMID:9578207. http: //dx.doi.org/10.1046/j.1365-2648.1998.00594.x

[21] Thygesen K, Alpert JS, White HD. Universal definition of myocardial infarction. Eur Heart J. 2007; 28: 2525-38. PMID:17951287. http://dx.doi.org/10.1093/eurheartj/ehm355

[22] Kwaliteitsinstituut voor de gezondheidszorg CBO. Richtlijn Behandeling van tabaksverslaving. Alphen a/d Rijn: van Zuiden; 2004.

[23] Tabachnick BG, Fidell, LS. 5th ed. Using multivariate statistics. Boston: Allyn \& Bacon; 2007.

[24] Mudde AN, Willemsen MC, Kremers S, de Vries H. Meetinstrumenten: voor onderzoek naar stoppen met roken. Den Haag: Stivoro; 2000.

[25] Ônpuu S, Negassa A, Yusuf S. INTER-HEART: a global study of risk factors for acute myocardial infarction. Am Heart J. 2001; 141: 711-21. PMID:11320357. http://dx.doi.org/10.1067/mhj . 2 001.114974

[26] van Asseldonk GAEG, van Duinen JJ, Former-Boon M, van Nuland R. Zakboek ziektegerelateerde ondervoeding bij volwassenen. 1st ed. Houten: Bohn Stafleu van Loghum; 2007. http://dx.doi .org/10.1007/978-90-313-8884-4

[27] Kwaliteitsinstituut voor de gezondheidszorg CBO. Richtlijn Diagnostiek en behandeling van obesitas bij volwassenen en kinderen. Alphen a/d Rijn: van Zuiden; 2008.

[28] Jafary FH, Aslam F, Mahmud H, Waheed A, Shakir M, Afzal A, et al. Cardiovascular health knowledge and behavior in patient attendants at four tertiary care hospitals in Pakistan - a cause for concern. BMC Public Health. 2005; 5: 124. PMID:16309553. http: //dx.doi.org/10.1186/1471-2458-5-124

[29] Rice J, Kovac V, Kraft P, Moan S. Predicting the intention to quit smoking and quitting behaviour: extending the theory of planned behaviour. Br J Health Psychol. 2008; 13: 291-310. PMID:17535498. http://dx.doi.org/10.1348/135910707X187245
[30] Conner M, Norman P. Body weight and shape control: examining component behaviours. Appetite. 1996; 27: 13550. PMID:8937618. http://dx.doi.org/10.1006/appe.1996 .0041

[31] Conner M, Warren R, Close S, Sparks P. Alcohol consumption and the theory of planned behavior: an examination of the cognitive mediation of past behavior. J Appl Soc Psychol. 1999; 29(8): 16761704. http://dx.doi.org/10.1111/j.1559-1816.1999.tb0 2046. $\mathrm{x}$

[32] Jackson C, Lawton R, Knapp P, Raynor DK, Conner M, Lowe $\mathrm{C}$, et al. Beyond intention: do specific plans increase health behaviours in patients in primary care? A study of fruit and vegetable consumption. Soc Sci Med. 2005; 60: 2383-91. PMID:15748685. http://dx.doi.org/10.1016/j.socscimed.2004.10.014

[33] Lippke S, Ziegelmann JP. Understanding and modeling health behavior: the multi-stage model of health behavior change. J Health Psychol. 2006; 11(1): 37-50. PMID:16314379. http://dx.doi.o rg/10.1177/1359105306058845

[34] Brislin RW. Back-translation for cross-cultural research. Journal of Cross-cultural Psychology. 1970; 1: 185-216. http://dx.doi.o $\mathrm{rg} / 10.1177 / 135910457000100301$

[35] Lynn MR. Determination and quantification of content validity. Nurs Res. 1986; 35: 382-85. PMID:3640358. http://dx.doi.org/1 0.1097/00006199-198611000-00017

[36] Polit DF, Beck CT. Nursing research: generating and assessing evidence for nursing practise. 9th ed. Philadelphia: Lippincott Williams \& Wilkins; 2011.

[37] Kline P. The handbook of psychological testing. 2nd ed. London: Routledge; 1993.

[38] Terwee CB, Bot SDM, de Boer MR, van der Windt DAWM, Knol DL, Dekker J, et al. Quality criteria were proposed for measurement properties of health status questionnaires. J Clin Epidemiol. 2007; 60: 34-42. PMID:17161752. http://dx.doi.org/10.1016/j·j clinepi.2006.03.012

[39] Knapp RB. Basic statistics for nurses. 2nd ed. Albany: Delmar Publishers; 2000.

[40] Bandura A. Self-efficacy: the exercise of control. New York: W.H. Freeman Company; 1997.

[41] Brink E, Karlson BW, Hallberg LRM. Readjustment 5 months after a first time myocardial infarction: reorienting the active self. $J$ Adv Nurs. 2006; 53(4): 403-11. PMID:16448483. http://dx.doi.o $\mathrm{rg} / 10.1111 / \mathrm{j} .1365-2648.2006 .03737 . \mathrm{x}$

[42] van Steenkiste B, van der Weijden T, Timmermans D, Vaes J, Stoffers J, Grol R. Patients' ideas, fears and expectations of their coronary risk: barriers for primary prevention. Patient Educ Couns. 2004; 55: 301-7. PMID:15530768. http://dx.doi.org/10.10 $16 / j \cdot$ pec. 2003.11.005

[43] Ferguson L. External validity, generalizability and knowledge utilization. J Nurs Scholarsh. 2004; 36(1): 16-22. PMID:15098414. http://dx.doi.org/10.1111/j.1547-5069.2004.04006.x 